\title{
Effect of the Compression Therapy Guided by Unna Boots on the Quality of Life and Complications in Patients with Lower Limb Venous Ulcers
}

\author{
YAN ZOU, SIMEI WANG, H. ZHOU AND LI ZHANG* \\ Department of Hand and foot surgery, Affiliated Nanhua Hospital, University of South China, Hengyang, Hunan 421002, \\ China
}

Zou et al.: Effect of the Compression Therapy in Patients with Lower Limb Venous Ulcers

\begin{abstract}
Venous ulcers are one of the public problems in the world at present, which has a great impact on human life and spirit. Therefore, this paper explores the therapeutic effect of the compression therapy guided by Unna boots on patients with lower limb venous ulcers. A total of 90 venous ulcers patients who were treated in our hospital from June 2016 to June 2019 were collected, the patients received the compression therapy guided by Unna boots, and the Unna boots were replaced every two w for 3 mo. The ulcer area and cure rate of the patients before and after treatment were evaluated, and the changes of quality in life and mental state of the patients were evaluated by the mean opinion score item short from health survey (SF-36). After one mo of treatment, the cure rate of the patient was $61.11 \%$, the focus showed epithelialization, and the cure rate reached $91.11 \%$ after 3 mo. The results of the SF-36 survey showed that the average score of patients increased to 57.80 after one mo of treatment and to $\mathbf{7 5 . 6 6}$ after three mo of treatment. At the same time, the physical function and general health scores of all patients were significantly improved after 3 mo of treatment. Before treatment, the average scores of social communication, role-emotional, and mental health in all patients were lower. After one mo of treatment, the average score of these evaluation indexes gradually increased. After 3 mo of treatment, the average score of these evaluation indexes was 4 times higher than that before treatment, and the difference before and after treatment was significant $(p<0.05)$. The results show that the compression therapy guided by Unna boots is effective in the treatment of lower limb venous ulcers, which can not only improve the quality of life of patients, but also help patients to restore self-confidence and self-esteem, and contribute to the recovery of patients.
\end{abstract}

Key words: Venous ulcers; compression therapy; unna boot; quality of life meta

Many Venous ulcers (VUL) were a major public health problem in the world. Because of its high incidence, it has a great impact on the social economy ${ }^{[1]}$. VUL was a skin lesion that affects $1 / 3$ of the lower legs, accounting for about $70 \%-90 \%$ of all leg ulcer cases. VUL was associated with the chronic venous insufficiency, which was the main cause of leg ulcers. This venous insufficiency was common in the elderly ${ }^{[2]}$. VUL makes the patients lose productivity and retire with disability due to unbearable pain. Some studies have found that in addition to restricting the patients daily life and leisure activities, VUL may also damage the patient's quality of life (QoL) and self-esteem, and even lead to depression $^{[3]}$. When the wound appears, the movement of the patients was limited and the pain was unbearable. In addition, the exudate and smell of the wound will affect the patient's way of life. Because some wounds may take several mo to heal ${ }^{[4]}$, the patients often feel frustrated and hopeless about the treatment. Compression therapy was often carried out with a stretch hose, bandages, pressure bandages or Unna boots, which was an effective means of VUL treatment ${ }^{[5]}$. As the pressure exerted on the leg moves from the ankle to the knee, its intensity gradually decreases, and the hydrostatic pressure of the intravascular increases, thus reversing the adverse consequences of standing for a long time ${ }^{[6,7]}$. In $40-95 \%$ cases, compression therapy can cure VUL completely, and improve the QoL and functional status of VUL patients ${ }^{[7-11]}$. Even the compression therapy can also promote the healing of VUL, prevent a recurrence, and improve the QoL, selfesteem, and well-being. However, the therapeutic effect of Unna boots on patients has not been reported. Therefore, in this study, Unna boots were used to treat patients and its therapeutic effect and psychological changes were analyzed. A total of 90 patients with VUL 
treated in our hospital from June 2016 to June 2019 were collected. Inclusion criteria: the age of the patients were more than $18 \mathrm{y}$ old and had ulcers for at least $1 \mathrm{y}$. The ankle brachial index (ABI) was between 0.8-1.0. Classified according to tissue type and exudate. Exclusion criteria: the patients had arterial ulcer of lower extremities, systemic important organ failure, diabetes, and severe cognitive impairment. All the patients were given basic treatment: debridement of the wound and surrounding skin with An'erdian III disinfectant, then local cleaning with $0.9 \%$ chloride cotton ball. However, povidine iodine antiseptic solution can also be used to clean the wound which is believed to be more efficacious, thus main the wound sterile. Gently remove the soft necrotic tissue from the wound with forceps, tweezers or scissors, and dry with sterile gauze. The ulcer wound was treated with calcium sodium alginate dressing, covered with the aseptic application and fixed with adhesive tape. Unna boots were used to guide compression therapy, and replaced every $2 \mathrm{w}$. This study lasted for $3 \mathrm{mo}$. The data were collected on the $\mathrm{d}$ of the patient visit, 1 mo later, 3 mo later, and the follow-up period ( $4^{\text {th }}$ mo later). According to the existing evaluation survey scheme, the MOS item short from health survey (SF-36) was used to evaluate QoL ${ }^{[8]}$. SF-36 was a general, multi-dimensional health survey, consisting of 36 questions, covering 6 areas: physical function, physical pain, general health, social communication, role-emotional, and mental health. The specific details were as follows: The physical function mainly assesses how the individuals perform tasks, such as dressing, bathing, walking, and climbing stairs; The physical pain mainly assesses the pain an individual has experienced during the assessment, as well as the limitations of symptoms on the patients daily life; The general health status mainly assesses how individuals view their own health and their views on the future health; The social communication mainly assesses how the emotional health affects work and other daily activities; The role-emotion mainly assesses the normal social activities time give up by the patients because of their physical or emotional state; The mental health mainly assesses the damage to life caused by anxiety, depression, happiness, calmness and other emotions. All patients in the study were independently evaluated and scored. 0 means extremely unhealthy, 100 means very healthy, and the higher the score, the better the health. SPSS 20.0 was used for statistical analysis, the measurement data was expressed by $(\mathrm{x} \pm \mathrm{s})$ and analyzed by the t-test, and the counting data were analyzed by $\chi 2$ test. $\mathrm{p}<0.05$ means the difference was statistically

significant. Among the selected 90 patients, 62 patients $(68.89 \%)$ were older than 60 y old, 48 females $(53.33 \%)$ and 63 retirees $(70 \%)$ Table 1 . Before treatment, the area of ulcer ranged from $16-20 \mathrm{~cm}^{2}$. One mo after the compression therapy with unna boots, the lesions of 55 patients $(61.11 \%)$ was epithelialized. And three mo later, 82 patients $(91.11 \%)$ were cured, the difference was statistically significant ( $\mathrm{p}<0.05$, fig. 1$)$. Before treatment, the average SF-36 score of the patients was low, which was only 16.50. After one mo of treatment, the average score increased to 57.80. After 3 mo of treatment, the average score increased to 75.66 (fig. 2). The difference before and after treatment was statistically significant $(\mathrm{p}<0.05)$, indicating that the QoL of these patients was significantly improved. Before treatment, the average scores of physical function and general health in all patients were lower, while the physical pain scores were significantly higher (fig. 3). After 3 mo of treatment, the average scores of these evaluation indexes were significantly improved $(p<0.05)$, indicating that the symptoms and QoL of these patients were significantly improved. Before treatment, the average scores of social communication, role-emotional, and mental health in all patients were lower (fig. 4). After one mo of treatment, the average score of these evaluation indexes gradually increased. After 3 mo of treatment, the average score of these evaluation indexes was 4 times higher than that before treatment, and the difference before and after treatment was significant $(\mathrm{p}<0.05)$. Lower limb VUL was considered as a public health problem, which has a significant social impact on the patients, their families, and the whole health system ${ }^{[9]}$. The incidence of VUL was higher in the female and people over $61 \mathrm{y}$ old, and most of these ulcers affect the social relations and work of the patients ${ }^{[10,11]}$. In this study, most of the participants were older than $61 \mathrm{y}$ old and were female or retired, which was basically consistent with the previous studies. VUL mainly affects the female, which may be

TABLE 1: GENERAL INFORMATION OF PATIENTS PARTICIPATING IN THE STUDY

\begin{tabular}{lc}
\hline & Number of cases \\
\hline Age & \\
$\leq 60$ & 28 \\
$>60$ & 62 \\
Sex & \\
Male & 42 \\
Female & 48 \\
Employment situation & \\
On-job & 27 \\
Retreat & 63 \\
\hline
\end{tabular}




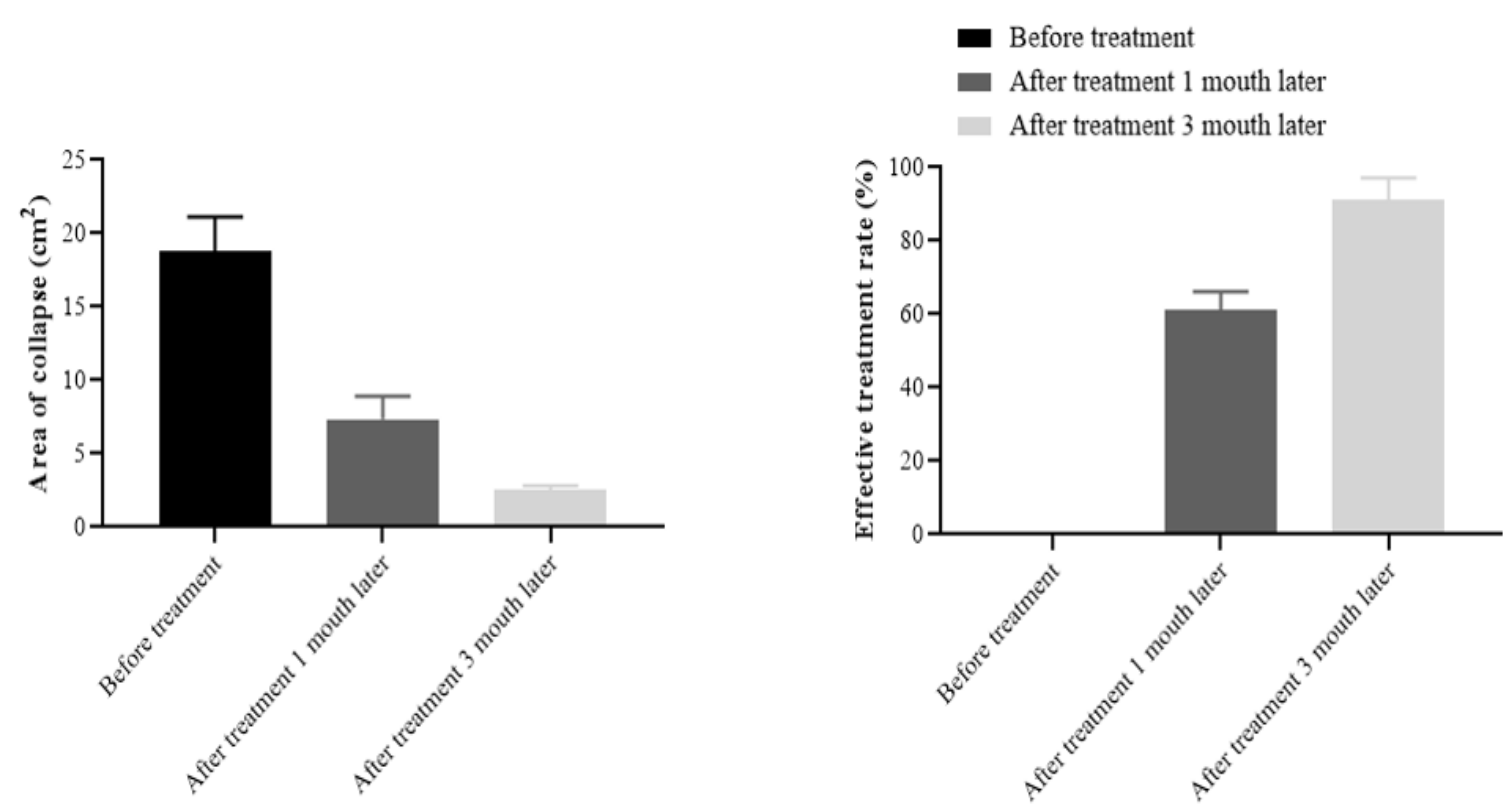

Fig. 1: Changes of the ulcer area and cure rate of patients before and after treatment

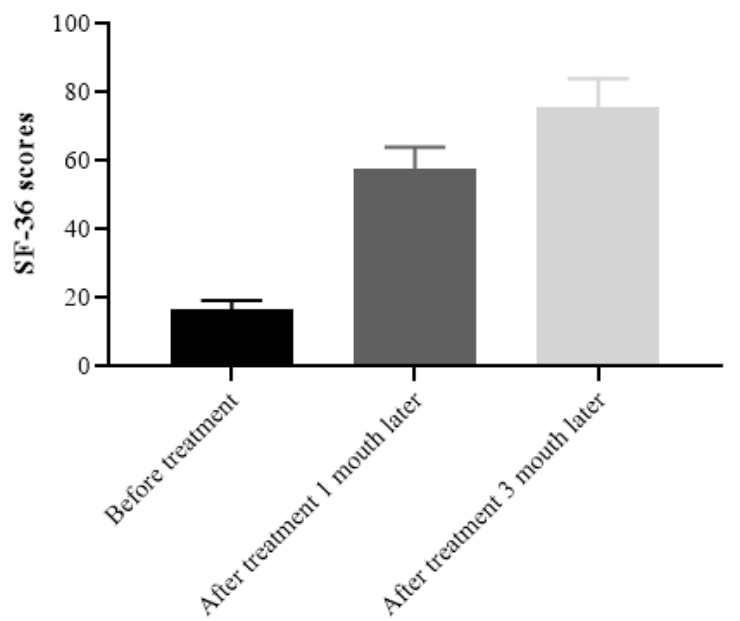

Fig. 2: SF-36 score before and after treatment

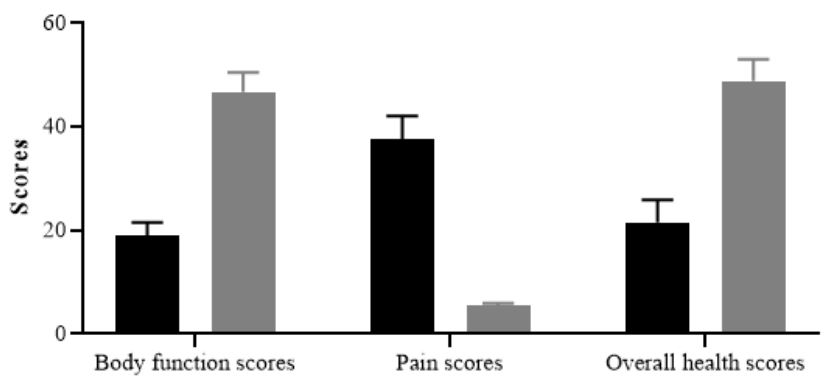

Fig. 3: Physical function, physical pain, and general health score of the patients before and after treatment.

related to the pregnancy and female sex hormones ${ }^{[2,9]}$. Before treatment, the ulcer area of the patient was $16-20 \mathrm{~cm}^{2}$. However, after 3 mo of compression therapy, the skin lesions in 82 patients $(91.11 \%)$ were healed. In the treatment of VUL, the most important thing is to improve the venous reflux, which can be achieved by raising the affected limb and compression therapy ${ }^{[12]}$.

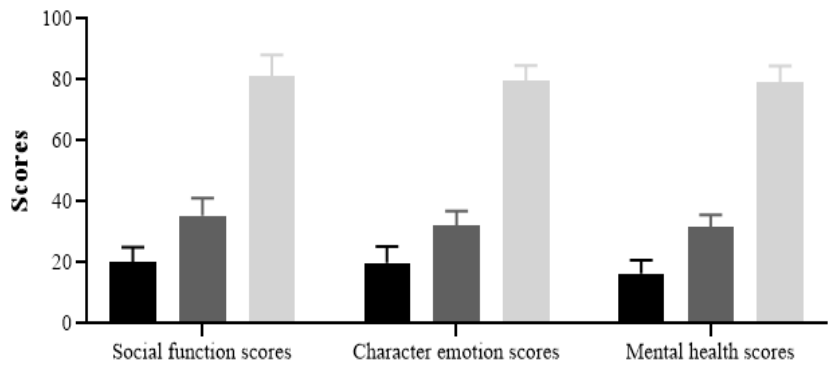

Fig. 4: Social communication, role-emotional, and mental health score of the patients before and after treatment.

The conventional therapy, improves vein circulation in your legs and treat swelling, by applying a firm compression bandage over the affected leg. These bandages are designed to squeeze your legs and encourage blood to flow upwards towards your heart. Compression therapy was the control measure of venous hypertension and the key to the effective treatment of VUL, which is often realized by stretch hose, elastic bandages or unna boots. The compression intensity of compression therapy gradually decreases from the ankle to knee to reverse the side effects of long standing posture and increase the hydrostatic pressure ${ }^{[13]}$. After compression therapy on VUL patients, about $40 \%-95 \%$ of the cases can be completely cured, and the QoL and functional ability of the patients can be improved $^{[14,15]}$. In recent decades, people pay more attention to QoL. QoL was originally used in other research areas, and later introduced into health, known as health-related quality of life (HRQoL), which can transform the subjective indicators into the quantitative indicators. The evaluation of QoL in patients with VUL 
was an important indicator of the evolution of wound healing. VUL causes changes in the patient's limited mobility, unbearable pain, exudate and the stench of decay. These changes have negative effects on patient's psychology, family relationship and social participation, and seriously affect patients QoL. In this study, the average SF-36 score of the patients before treatment was low, indicating a decrease in QoL. After 1 mo of compression therapy guided by unna boots, QoL was significantly improved. After 3 mo of treatment, almost all the patients had good QoL. In a study of 74 patients, the impact of lower limb VUL on patient's lives was assessed, suggesting that the patients suffered from pain and drastic changes in $\mathrm{QoL}^{[12]}$. Another study that assessed the effects of ulcers on patient's daily lives found that the patients with ulcers showed pain, low self-esteem and social isolation. This may be related to that the patients were unable to participate in some daily activities harmoniously, thus reducing their selfesteem, self-image and QoL. However, it is worth noting that the results of this study found that the pain intensity of patients with ulcer healing decreased, the self-esteem and QoL also improved. The results showed that the compression therapy guided by Unna boots is effective in the treatment of lower limb VUL, which can not only improve the QoL of patients, but also help patients to restore self-confidence and self-esteem, and contribute to the recovery of patients.

\section{Author's contributions}

Li Zhang conceived and designed the experiments; H. Liao, Simei Wang and H. Zhou performed the experiments; Yan Zou analyzed the data and wrote the paper.

\section{Acknowledgements}

This work was supported by Affiliated Nanhua Hospital, University of South China.

\section{Conflict of interests:}

The authors declared no conflict of interest.

\section{REFERENCES}

1. Abbade LP, Lastoria S, Rollo Hde A. Venous ulcer: clinical characteristics and risk factors. Int J Dermatol 2011;50:405-11.

2. Kanjoor JR. Venous ulcer: current concepts. Indian J Plast Surg 2011;44:109-11.
3. Shanley E, Moore Z, Patton D, O'Connor T, Nugent L, Budri AM, et al. Patient education for preventing recurrence of venous leg ulcers: a systematic review. J Wound Care 2020;29:79-91.

4. de Jesus Pereira MT, Magela Salome G, Guimarães Openheimer D, Cunha Esposito VH, Aguinaldo de Almeida S, Masako Ferreira L. Feelings of powerlessness in patients with diabetic foot ulcers. Wounds 2014;26:172-7.

5. Cardoso LV, Godoy MFG, Czorny RCN, Godoy JMP. Using bioelectrical impedance analysis to compare the treatment of edema with the Unna's boot and non-compression in individuals with venous ulcers. J Vasc Nurs 2019;37:58-63.

6. Abbade LP, Lastoria S. Approach to patients with venous leg ulcer. An Bras Dermatol 2006;81:509-22.

7. Wound, Ostomy and Continence Nurses Society (WOCN) Wound Committee, Association for Professionals in Infection Control and Epidemiology, Inc (APIC). 2000 Guidelines Committee. Clean vs. sterile dressing techniques for management of chronic wounds: a fact sheet. J Wound Ostomy Continence Nurs 2012;39:S30-S4.

8. Davis J, Gray M. Is the Unna boot bandage as effective as a four-layer wrap for managing venous leg ulcers? J Wound Ostomy Continence Nurs 2005;32:152-6.

9. Nelson EA, Bell-Syer SE. Compression for preventing recurrence of venous ulcers. Cochrane Database Syst Rev 2014;9:CD002303.

10. Milic DJ, Zivic SS, Bogdanovic DC, Perisic ZD, Milosevic $\mathrm{ZD}$, Jankovic RJ, et al. A randomized trial of the Tubulcus multilayer bandaging system in the treatment of extensive venous ulcers. J Vasc Surg 2007;46:750-5.

11. Macedo EAB, Nogueira MIS, Torres SMSGSO, Torres GV. Effectiveness of compression therapy in the healing of venous ulcers: a literature review. Fiep Bulletin Online 2009.

12. World Union of Wound Healing Societies (WUWHS). Principles of best practice: compression in venous leg ulcers. A consensus document. MEP 2008.

13. Salomé GM, Maria de Souza Pellegrino D, Blanes L, Ferreira LM. Self-esteem in patients with diabetes mellitus and foot ulcers. J Tissue Viability 2011;20:100-6.

14. Paul JC, Pieper B, Templin TN. Itch: association with chronic venous disease, pain, and quality of life. J Wound Ostomy Continence Nurs 2011;38:46-54.

15. Busseri MS. Examining the structure of subjective well-being through meta-analysis of the associations among positive affect, negative affect, and life satisfaction. Pers Individ Differ 2018;122:68-71.

This is an open access article distributed under the terms of the Creative Commons Attribution-NonCommercial-ShareAlike 3.0 License, which allows others to remix, tweak, and build upon the work non-commercially, as long as the author is credited and the new creations are licensed under the identical terms

This article was originally published in a special issue,
"Biomedical Research in Clinical and Preclinical
Pharmaceutics" Indian J Pharm Sci 2020:82(5)Spl
issue7;130-133

